\title{
Long-term trends in colorectal cancer: incidence, localization, and presentation
}

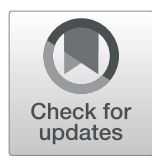

Øystein Høydahl ${ }^{1,2^{*}}$ (D), Tom-Harald Edna ${ }^{1,2}$, Athanasios Xanthoulis ${ }^{1,2}$, Stian Lydersen ${ }^{3}$ and

Birger Henning Endreseth ${ }^{4,2}$

\begin{abstract}
Background: The purpose of this study was to assess trends in incidence and presentation of colorectal cancer (CRC) over a period of 37 years in a stable population in Mid-Norway. Secondarily, we wanted to predict the future burden of CRC in the same catchment area.

Methods: All 2268 patients diagnosed with CRC at Levanger Hospital between 1980 and 2016 were included in this study. We used Poisson regression to calculate the incidence rate ratio (IRR) and analyse factors associated with incidence.

Results: The incidence of CRC increased from 43/100,000 person-years during 1980-1984 to 84/100,000 personyears during 2012-2016. Unadjusted IRR increased by 1.8\% per year, corresponding to an overall increase in incidence of $94.5 \%$. Changes in population (ageing and sex distribution) contributed to $28 \%$ of this increase, whereas $72 \%$ must be attributed to primary preventable factors associated with lifestyle. Compared with the last observational period, we predict a further $40 \%$ increase by 2030, and a $70 \%$ increase by 2040 . Acute colorectal obstruction was associated with tumours in the left flexure and descending colon. Spontaneous colorectal perforation was associated with tumours in the descending colon, caecum, and sigmoid colon. The incidence of obstruction remained stable, while the incidence of perforation decreased throughout the observational period. The proportion of earlier stages at diagnosis increased significantly in recent decades.

Conclusion: CRC incidence increased substantially from 1980 to 2016, mainly due to primary preventable factors. The incidence will continue to increase during the next two decades, mainly due to further ageing of the population.
\end{abstract}

Keywords: Colorectal cancer, Incidence, Presentation, Trends, Epidemiology

\section{Background}

Colorectal cancer (CRC) is the fourth most common cancer and the second most common cause of cancer death globally [1]. In 2018 the age-standardized (world) incidence for CRC was $19.7 / 100,000$, higher in males than in females $(23.6 / 100,000$ vs. $16.3 / 100,000)$ [2]. The

\footnotetext{
* Correspondence: oystein.hoydahl@gmail.com

'Department of Surgery, Levanger Hospital, Nord-Trøndelag Hospital Trust, Levanger, Norway

${ }^{2}$ IKOM Department of Clinical and Molecular Medicine, NTNU, Norwegian University of Science and Technology, Trondheim, Norway

Full list of author information is available at the end of the article
}

distribution of CRC burden varies widely, with increasing incidence in countries where the human development index (HDI) is high [3]. Among the Nordic countries, Denmark and Norway have the highest incidence. In Norway the age-standardized (world) incidence of CRC in 2012-16 was 44.9/100,000 in males and 37.4/ 100,000 in females. The estimated annual increases during the last 10 years were $0.5 \%$ among males and $1.1 \%$ in females [4]. The incidence of CRC is expected to increase by $33 \%$ in $2024-2028$, caused mainly by an ageing population [5].

(c) The Author(s). 2020 Open Access This article is licensed under a Creative Commons Attribution 4.0 International License, which permits use, sharing, adaptation, distribution and reproduction in any medium or format, as long as you give appropriate credit to the original author(s) and the source, provide a link to the Creative Commons licence, and indicate if changes were made. The images or other third party material in this article are included in the article's Creative Commons licence, unless indicated otherwise in a credit line to the material. If material is not included in the article's Creative Commons licence and your intended use is not permitted by statutory regulation or exceeds the permitted use, you will need to obtain permission directly from the copyright holder. To view a copy of this licence, visit http://creativecommons.org/licenses/by/4.0/ The Creative Commons Public Domain Dedication waiver (http://creativecommons.org/publicdomain/zero/1.0/) applies to the data made available in this article, unless otherwise stated in a credit line to the data. 
In Western countries CRC is primarily a disease of the elderly, with a peak incidence at around 70 years of age. The aetiology is multifactorial, and most patients are affected in a sporadic manner. Approximately threequarters have a negative family history [6]. It is well documented that primary preventable causes such as unfavourable diet, obesity, alcohol, smoking, and low physical activity increase the risk of CRC [7].

Based on a continuous exposure to these risk factors, and an expected ageing of the population [8], the number of patients with CRC will grow in the coming years. Knowledge of trends in incidence and clinical characteristics of CRC patients is imperative to tailor diagnostic work-up and treatment, as well as in development of a strategy to meet future changes in the patient population. As the burden on the health care system continues to rise, it will be important to focus on quality and optimal utilization of resources through adequate organization of the services, standardized care pathways, and individualised treatment.

The focus on primary prevention of CRC will continue, but further achievements in reducing CRC incidence are uncertain and will possibly affect future generations. Secondary prevention by screening programs has been proven to reduce the incidence of CRC among attendees in the long run [9]. In Norway, national screening for CRC will be implemented for patients in their mid-fifties in the coming years. Although important, these preventive measures will not have a significant impact on CRC incidence among the rapidly increasing elderly part of the Norwegian population.

This study was designed to analyse epidemiologic trends in patients diagnosed with CRC for nearly four decades, with respect to incidence, presentation of disease, and stage. Secondarily we wanted to use this knowledge to estimate the future burden of CRC.

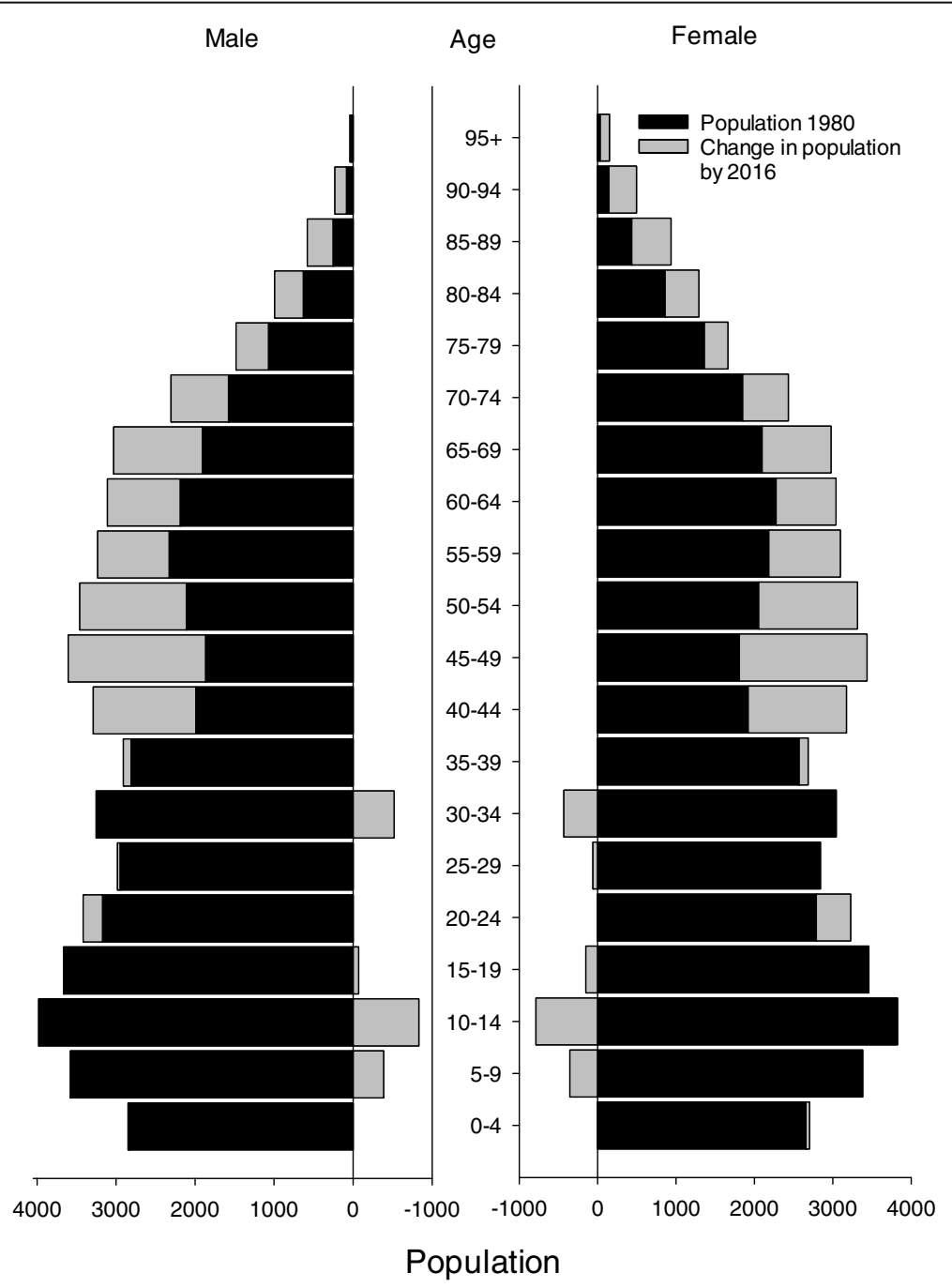

Fig. 1 Population in Levanger Hospital's catchment area in 1980 and in 2016, categorized by age groups 


\section{Methods}

All patients with CRC admitted to Levanger Hospital during the 37-year period between January 1980 and December 2016 were included in this study. Levanger Hospital serves as the primary hospital for 10 municipalities in North-Trøndelag County, located in Mid-Norway. The county consists of a long coastline as well as large farmlands and forests. The population lives in small towns, villages, or in rural areas. Agriculture is the most important industry. Mean income and education level are slightly less than the national average. The population rose from 83,890 in 1980 to 99,566 in 2016 (a 19\% increase). Figure 1 displays changes in the distribution of age in our catchment area and compares 1980 with 2016. Figure 2 displays the population in 2018 and the estimated population in 2040 [8]. The catchment area remained unchanged throughout the observation period. The patients represented an unselected population.
The patients were identified through the discharge diagnoses in the patient administrative system of the hospital, using ICD-8 diagnosis codes 153.01 to 154.19 , ICD-9 codes 153.0 to 154.1 , and the ICD-10 codes C18.0 to C20. Patients with cancer of the appendix (C18.1) were excluded. Data were retrieved from the health records of all patients. We registered demographic variables, date of admission, presentation (bowel obstruction or spontaneous perforation), localization of the tumour, and stage according to the TNM classification of malignant tumours, 6th edition [10]. The database was confirmed by comparing data from the Norwegian Cancer Registry 1980-2016.

Patients with malignancies other than adenocarcinomas (pseudomyxoma peritonei, neuroendocrine tumours, sarcomas [GIST], and lymphomas) were excluded, leaving 2268 patients with CRC in the final cohort. A histological diagnosis of adenocarcinoma was

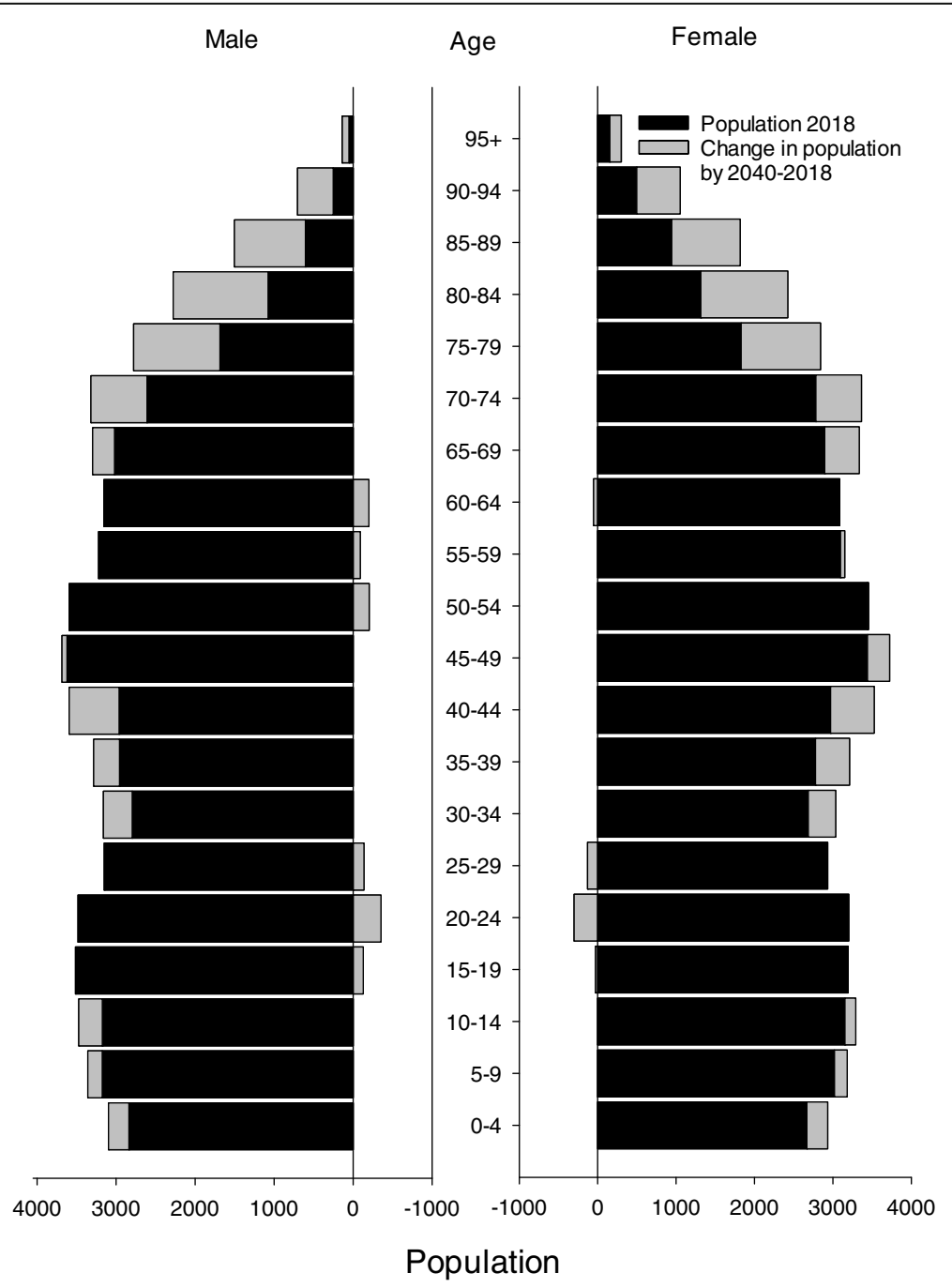

Fig. 2 Population in Levanger Hospital's catchment area in 2018 and estimated population in 2040 
available in 2159 patients (95.2\%). In the remaining 109 patients (4.8\%) the diagnosis was made without a biopsy and based upon a combination of CT-findings, CEA level, colon X-ray, clinical findings, and medical history. These were older, frail patients not fit for surgery or oncological treatment.

Colonic cancer located from the caecum to the transverse colon was defined as right sided. Cancer located from the left flexure to the sigmoid colon was defined as left-sided colon cancer [11]. Rectal cancer was defined as cancer located within $15 \mathrm{~cm}$ of the anal verge, with upper, middle, and lower rectum distanced $12-15 \mathrm{~cm}$, $6-11 \mathrm{~cm}$, and $0-5 \mathrm{~cm}$ from the anal verge, respectively.

We categorized patients into five age groups: $<65$ years, 65-74 years, $75-79$ years, $80-84$ years, and $>85$ years. Trends in calendar years were analysed using fiveyear periods.

\section{Statistical analysis}

The Cochran-Armitage test was used to test for trends in proportions. Logistic regression analysis was used to test for association between intestinal obstruction and perforation at admission as dependent variables and different explanatory variables. Ordinal logistic regression was used to test associations in doubly ordered $\mathrm{r} \times \mathrm{c}$ tables, as in stage by decades. Multinomial logistic regression analysis was used in singly ordered $\mathrm{r} x \mathrm{c}$ tables, as in the localization of the tumour depending on decade.

The overall incidence of CRC was defined as the number of new cases of CRC in the defined population within 1 year. The incidence rate (IR) was defined as the incidence divided by the total person-time at risk during the same year. The incidence rate ratio (IRR) was defined as the ratio between two incidence rates. The incidence of cancer was analysed using Poisson regression with CRC as the dependent variable and sex, age in fiveyear intervals (20-24, 25-29, up to 90-94, 95-99), and calendar year from 1980 to 2016 as covariates. Nonlinear relationships were explored by using fractional polynomials [12].

Where relevant, we also adjusted the regression analyses for age, sex, year of diagnosis, and T-stage, which were a priori regarded as plausible confounders.

Age and sex distributions for the 10 municipalities around Levanger Hospital for every year from 1980 to 2016, and information on the expected numbers of males and females by 2030 and 2040, were obtained from Statistics Norway [8].

Two-sided $P$-values $<0.05$ were considered significant. Means were reported with the range (minimum to maximum) and standard deviation (SD) where relevant. Ninety-five percent confidence intervals (CI) were reported where relevant. Analyses were carried out in Stata 15, IBM SPSS Statistics 25, and StatXact 9.

\section{Results}

\section{Study population}

The characteristics of the 2268 patients diagnosed with CRC between 1980 and 2016 are presented in Table 1. There were 1194 (53\%) males and 1074 females. Twothirds $(n=1551,68 \%)$ of cases were colon cancers. The mean age in colon cancer patients was 72.2 (32.9-96.1, SD 11.1) years in males and 73.1 (20.3-99.6, SD 11.5) years in females. Corresponding numbers for rectal cancer patients were 70.9 (21.6-94.3, SD 10.7) and 70.4 (35.2-97.1, SD 12.0) years, respectively. The mean annual number of new CRC patients from 1980 to 1986 was 38 patients per year compared with 83 patients per year for 2007 to 2016. The group of patients above 85 years increased, representing $6 \%$ in the first period and $13 \%$ in the last period. We observed non-significant variations in tumour localization throughout the observation period. Figure 3 displays the distribution of patients according to sex and age throughout the study period.

\section{Incidence}

The overall unadjusted incidence rate during the 37 years was 66.1/100,000 person-years, 63.1/100,000 person-years in females, and $69.3 / 100,000$ person-years in males. During the first 5 years the overall incidence rate was 43/100,000 person-years, compared with 85/ 100,000 person-years during the last 5 years.

The incidence rate for CRC increased with every calendar year and with increasing age. The incidence rate increased by $1.2926 \%$ for each calendar year when age and sex were adjusted for. This corresponded to an increase in $60.8 \%\left(1.012926^{37}\right)$ throughout the entire observation period. When adjusted for age only, the increase in incidence rate was $1.2953 \%$ per year. Hence, a negligible proportion $(0.0027,1.2953 \%$ minus $1.2926 \%)$ of the increased incidence rate was attributed to sex. When neither age nor sex were adjusted for, the increase in incidence rate was $1.808 \%$ for each calendar year, corresponding a total increase of $94.1 \%\left(1.01808^{37}\right)$. The increase in incidence rate attributed to the ageing of the population and sex distribution was $0.512 \%$ (1.808\% minus $1.2926 \%$ ), equivalent to a $28 \%$ relative increase $(0.512 / 1.808=28 \%)$. Factors other than sex and ageing of the population were the main reasons for the incidence increase, and $72 \%$ of the observed increase must be attributed to them.

Table 2 shows the IRRs of CRC as a function of age and calendar year, for males and females separately. There was a significant increase in incidence rate for both sexes with calendar year and age, apart from left-sided colonic cancer for women and rectal cancer for men.

Figure 4a shows the absolute number of patients distributed by 5 -year age-groups and sex. Figure $4 \mathrm{~b}$ shows the same patients compared with the number of persons 
Table 1 Characteristics of CRC for each calendar period of admission

\begin{tabular}{|c|c|c|c|c|c|c|}
\hline Year & 1980-1986 & 1987-1996 & 1997-2006 & 2007-2016 & Total & $P$ value \\
\hline Patients & & & & & & $0.53^{a}$ \\
\hline Male & $136(51)$ & $270(54)$ & $341(51)$ & $447(54)$ & 1.194 & \\
\hline Female & $133(49)$ & $234(46)$ & $322(49)$ & $385(46)$ & 1.074 & \\
\hline Age & & & & & & $0.004^{b}$ \\
\hline$<65$ & $75(28)$ & $130(26)$ & $189(29)$ & $183(22)$ & 577 & \\
\hline $65-75$ & $83(31)$ & 179 (36) & $173(26)$ & $272(33)$ & 707 & \\
\hline $75-80$ & $50(19)$ & $76(15)$ & $122(18)$ & $142(17)$ & 390 & \\
\hline $80-85$ & $46(17)$ & $75(15)$ & $109(16)$ & $128(15)$ & 358 & \\
\hline$>85$ & $15(6)$ & $44(9)$ & $70(11)$ & $107(13)$ & 236 & \\
\hline Localization & & & & & & $0.29^{c}$ \\
\hline Right colon & $99(37)$ & $177(35)$ & $252(38)$ & $327(39)$ & 855 & \\
\hline Left colon & $78(29)$ & $168(33)$ & $211(32)$ & $239(29)$ & 696 & \\
\hline Rectum & $92(34)$ & $159(32)$ & $200(30)$ & $266(32)$ & 717 & \\
\hline \multicolumn{7}{|l|}{ Acute presentation } \\
\hline Colorectal obstruction & $23(8.6)$ & $57(11.3)$ & $63(9.5)$ & $88(10.6)$ & 231 & $0.69^{a}$ \\
\hline Perforation & $18(6.7)$ & $17(3.4)$ & $20(3.0)$ & $13(1.6)$ & 68 & $<0.001^{\mathrm{a}}$ \\
\hline \multicolumn{7}{|l|}{ Stage } \\
\hline I & $34(13)$ & $53(11)$ & $92(14)$ & $173(21)$ & 353 & $<0.001^{\circ}$ \\
\hline$\|$ & $81(30)$ & $163(32)$ & $243(37)$ & 309 (37) & 798 & \\
\hline III & $70(26)$ & 119 (24) & $133(20)$ & $174(21)$ & 495 & \\
\hline IV & $65(24)$ & $128(25)$ & $155(23)$ & $174(21)$ & 524 & \\
\hline Unknown & $19(7)$ & 41 (8) & $40(6)$ & $2(0.2)$ & 103 & \\
\hline
\end{tabular}

Values in parenthesis are percentages of column total

${ }^{a}$ Cochran-Armitage exact trend test

${ }^{b}$ Ordinal logistic regression with calendar period as covariate

c Multinomial logistic regression with calendar period as covariate

d Ordinal logistic regression with calendar period as covariate, for known stages

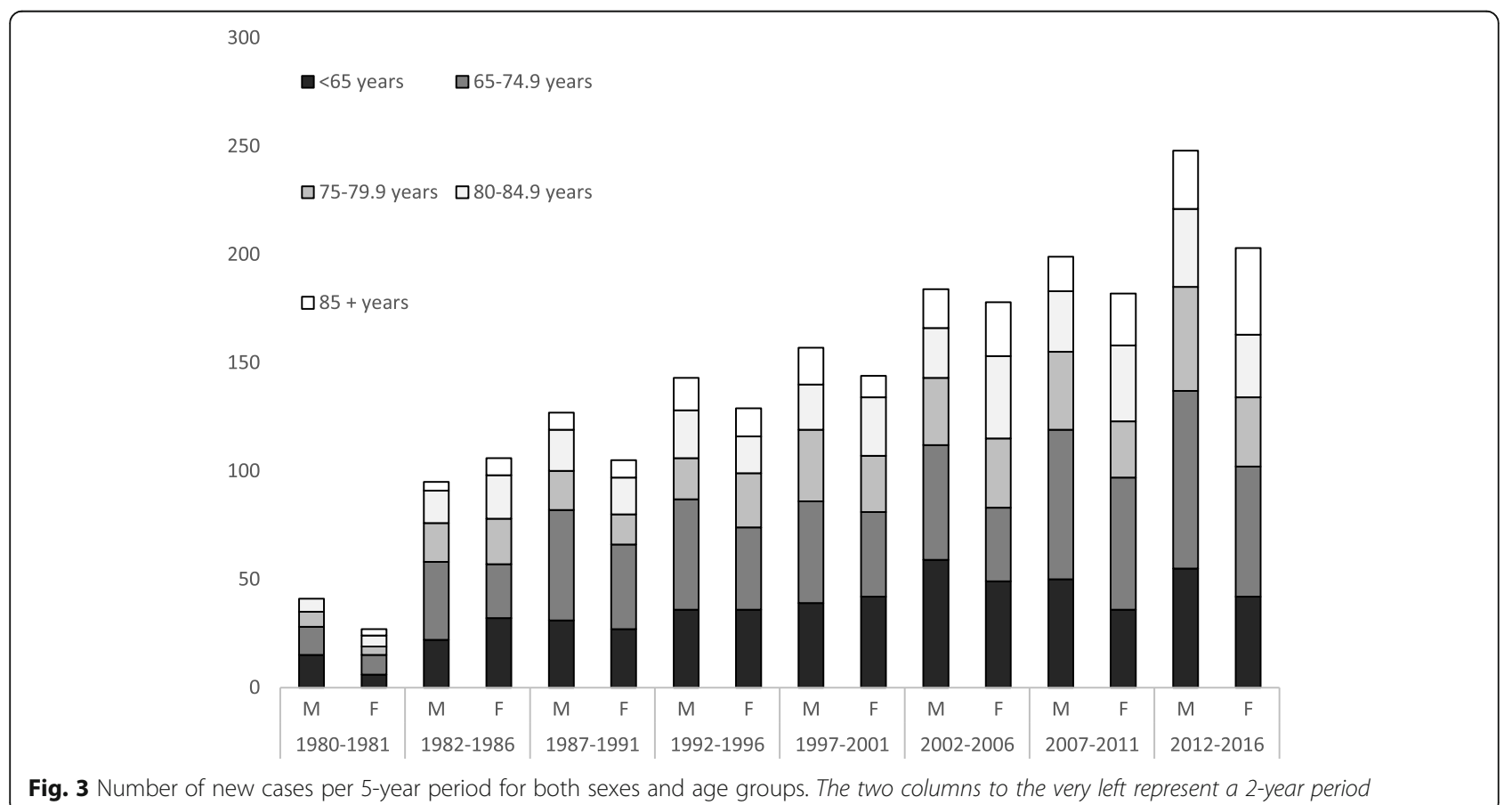

Fig. 3 Number of new cases per 5-year period for both sexes and age groups. The two columns to the very left represent a 2-year period 
Table 2 Factors associated with CRC. Adjusted IRRs from Poisson regression. Calendar year and age as covariates

\begin{tabular}{|c|c|c|c|c|}
\hline & Male & & Female & \\
\hline & IRR (Cl) & $P$ value & IRR (Cl) & $P$ value \\
\hline Total colorectal cance & & & & \\
\hline Calendar year & $1.0133(1.0078-1.0189)$ & $<0.001$ & $1.0127(1.0068-1.0186)$ & $<0.001$ \\
\hline Age (per 5 years) & $1.0807(1.0764-1.0850)$ & $<0.001$ & $1.0691(1.0650-1.0732)$ & $<0.001$ \\
\hline Right sided colonic c & & & & \\
\hline Calendar year & $1.0208(1.0111-1.0306)$ & $<0.001$ & $1.0148(1.0059-1.0238)$ & 0.001 \\
\hline Age (per 5 years) & $1.0887(1.0811-1.0964)$ & $<0.001$ & $1.0798(1.0730-1.0866)$ & $<0.001$ \\
\hline Left sided colonic car & & & & \\
\hline Calendar year & $1.0155(1.0055-1.0256)$ & 0.002 & $1.0093(0.9990-1.0197)$ & 0.077 \\
\hline Age (per 5 years) & $1.0797(1.0721-1.0872)$ & $<0.001$ & $1.0627(1.0557-1.0697)$ & $<0.001$ \\
\hline Rectal cancer $n=646$ & & & & \\
\hline Calendar year & $1.0042(0.9950-1.0136)$ & 0.37 & $1.0130(1.0013-1.0249)$ & 0.030 \\
\hline Age (per 5 years) & $1.0743(1.0674-1.0813)$ & $<0.001$ & $1.0607(1.0528-1.06856)$ & $<0.001$ \\
\hline
\end{tabular}

${ }^{a}$ Ninety-five patients admitted to Levanger Hospital from the area of Namsos Hospital, mostly because of centralization of rectal cancer during the later years, have been excluded from these incidence analyses. They were not included because that area was not an original part of the primary population area of Levanger Hospital

of the same sex and age in this area of Trøndelag. The figure shows that CRC was becoming more frequent as age increased.

Figure 5 shows the results of possibly nonlinear effects of age and calendar year for CRC, using fractional polynomials. The lower figures in Fig. 5 show a straight line as a function of age, for both males and females. This confirms that the assumption of a linear effect of age on the logarithm of incidence is a good approximation to reality in our data. In other words, the risk of colorectal cancer increases by a factor of approximately 1.081 per 5 years for males and 1.069 per 5 years for females (Table 2) throughout the lifetimes we have in our study. Regarding the effect of calendar year, the upper two figures indicate a nonlinear effect of calendar year: the increase in incidence was largest in the first years from
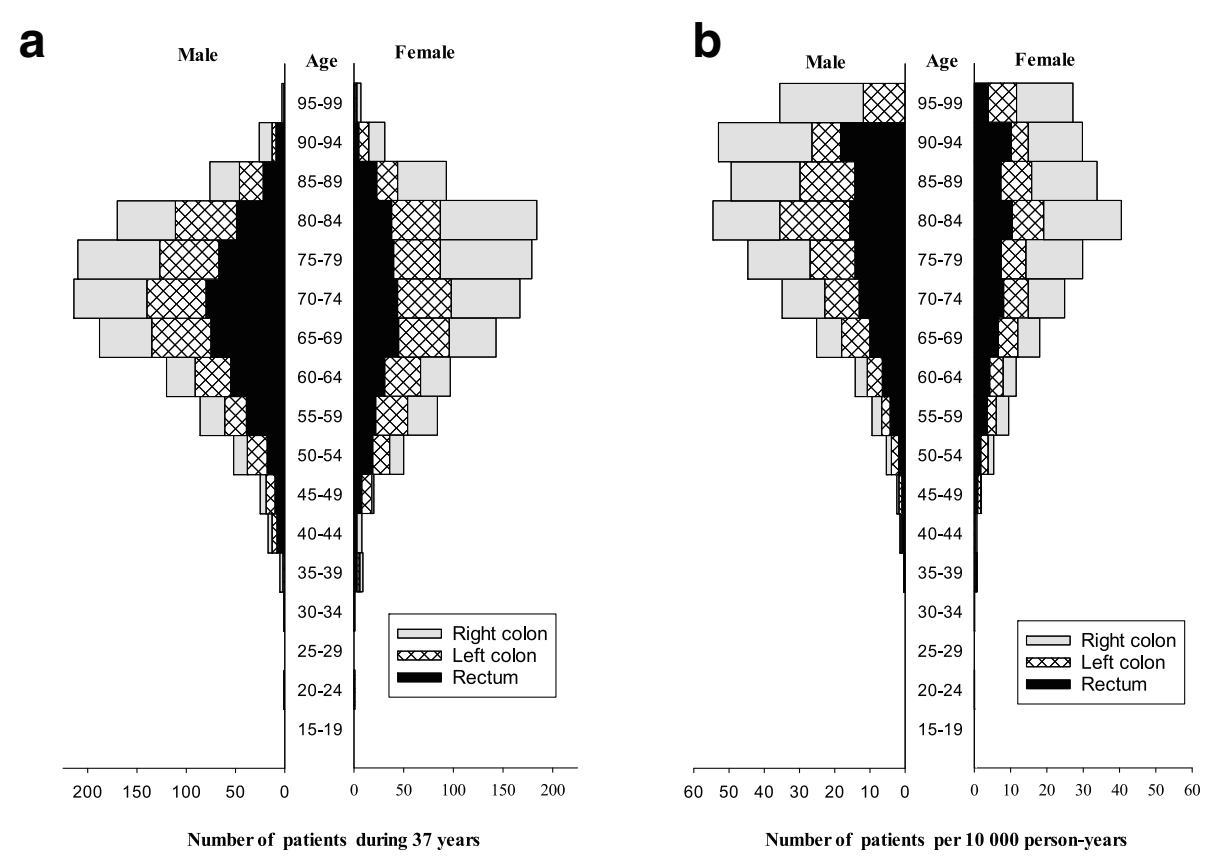

Fig. 4 a Number of new cases with colorectal cancer during a 37-year period (left). b Number of new cases per 10,000 person-years (right) 


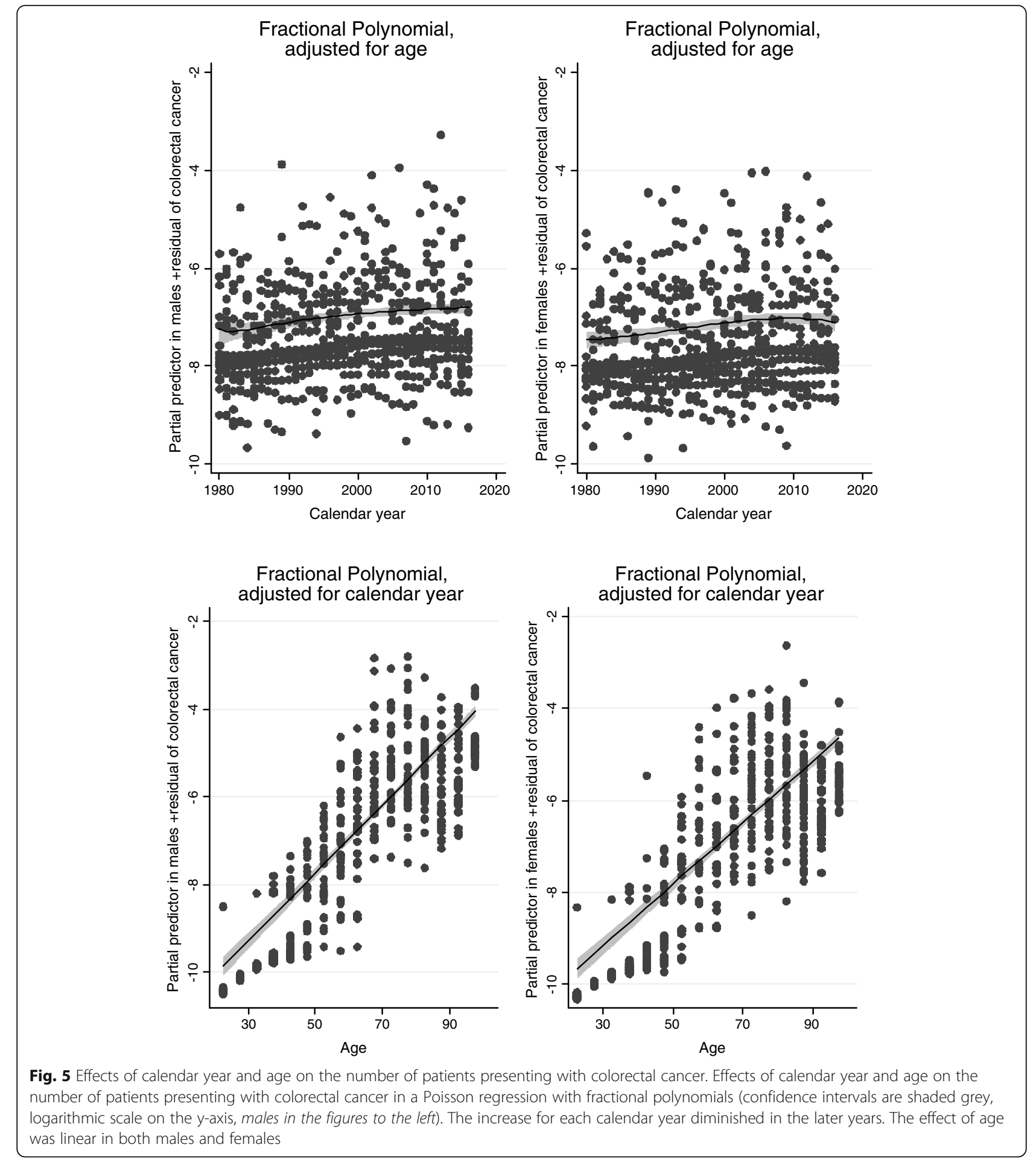

1980, and seems to have flattened out between 2000 and 2010. From around 2000 there was less of an increase or no increase in age-adjusted incidence.

\section{Predicting the future burden of colorectal cancer}

The results of the Poisson analysis with fractional polynomials showed that the calendar-year effect seemed to flatten out around 2000 to 2010 . The predicted numbers of CRC cases in future years are based on the mean incidence rates for the latest 10 years of the study period (2007-2016) for each 5-year age group, separately for males and females. A Poisson model was used to predict the number of cases occurring by 2030 and by 2040; see the results in Fig. 6. In the year 2030, the model 


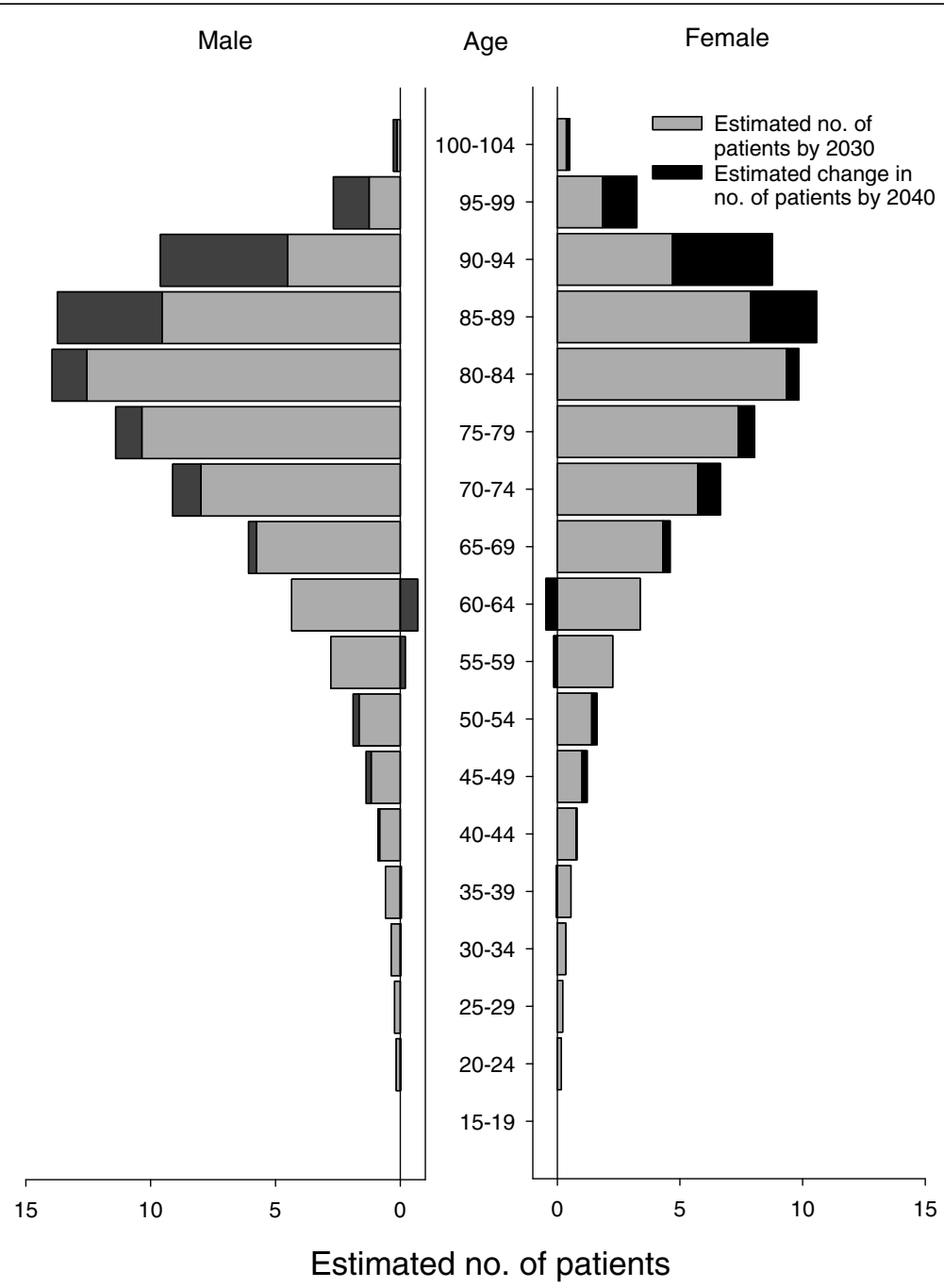

Fig. 6 Estimated numbers of new cases with CRC by 2030 and 2040

estimates a total of 116 (50\% prediction interval: 109-124) new CRC patients in our catchment area, including 65 males and 52 females. Corresponding numbers for the year 2040 are 79 males and 62 females, totalling 141 patients (50\% prediction interval: 133-150).

\section{Stage}

Stage for each time period is shown in Table 1. The proportion of earlier stages increased significantly in recent decades. There were substantially fewer patients with unknown stage. Table 3 shows stage as a dependent variable with regard to sex, age, decade, and localization of the obstructing tumour. The results of multivariable analyses showed that older age, diagnosis in recent years, and distal location were associated with earlier stages.

\section{Colorectal obstruction and perforation}

Acute colorectal obstruction was the presenting symptom in 231 of 2268 patients $(10.2 \%)$. Table 4 shows presentation with acute colorectal obstruction with regard to sex, age, calendar year, and localization of the obstructing tumour. Multivariable analysis showed that acute colorectal obstruction was associated most commonly with tumours in the left flexure and the descending and sigmoid colon. It was significantly less frequent with rectal tumours. There were no associations between colorectal obstruction and sex or age.

Spontaneous colorectal perforation occurred in 68 of 2268 patients $(3.0 \%)$. Table 5 shows spontaneous colorectal perforation with regard to sex, age, calendar year, and localization of the obstructing tumour. Perforation was associated with tumours in the descending colon (5.4\%), caecum (4.9\%), and sigmoid colon (4.8\%). Perforation became significantly less frequent as time passed, 
Table 3 Stage at presentation. Ordinal logistic regression with known stage at presentation as the dependent variable. ${ }^{a}$

\begin{tabular}{|c|c|c|c|c|}
\hline & Unadjusted odds ratio & $P$ value & Adjusted odds ratio & $P$ value \\
\hline Female sex & $1.03(0.89-1.20)$ & 0.69 & $0.99(0.84-1.15)$ & 0.85 \\
\hline Age & $0.994(0.987-1.001)$ & 0.080 & 0.99 (0.986-0.999) & 0.046 \\
\hline Year of diagnosis & $0.981(0.974-0.989)$ & $<0.001$ & $0.98(0.974-0.989)$ & $<0.001$ \\
\hline \multicolumn{5}{|l|}{ Location } \\
\hline Right colon & 1 & & 1 & \\
\hline Left colon & $0.86(0.72-1.03)$ & 0.11 & $0.83(0.69-1.004)$ & 0.055 \\
\hline Rectum & $0.64(0.53-0.77)$ & 0.004 & $0.62(0.51-0.75)$ & $<0.001$ \\
\hline
\end{tabular}

${ }^{a}$ Sex, age, year of diagnosis, and location of the primary tumour as covariates. Unadjusted, and adjusted for age, sex, and year

and was not associated with sex or increasing age. In the last period perforation occurred in $1.6 \%$ of the patients.

\section{Discussion}

\section{Incidence}

This observational survey was completed to assess epidemiological and clinical trends in CRC over a 37-year period, and to estimate future changes in the patient population. The overall incidence rate of CRC increased by $90 \%$ during the study period. Of this observed increase, $28 \%$ was attributed to changes in the population (age and sex), whereas $72 \%$ was related to other factors. According to our estimates, the number of new CRC patients, particularly octogenarians, will continue to rise in the coming years. We shall expect a $40 \%$ increase in
2030 and a $70 \%$ increase in 2040, compared with mean incidence rates the past 10 years.

The local incidence rate in our catchment area was somewhat below the national level in 1980-1984, but increased to the national level during the last 5 year period of the study [13]. Our county, as well as other rural areas of Norway, has undergone some urbanisation throughout this period. Differences in lifestyle among Norwegian citizens living in the cities and in the countryside are diminishing, and the population is to an increasing extent exposed to the same risk factors. Global patterns show a marked increase in the incidence of CRC in countries adopting modern Western living habits [3]. Norway has enjoyed rapid social and economic development since the 1970s, in great extent due to the oil industry. There has been an increase in the rates of

Table 4 Colorectal obstruction. Logistic regression with colorectal obstruction at presentation as the dependent variable ${ }^{a}$

\begin{tabular}{|c|c|c|c|c|c|}
\hline & Colorectal obstructions (\%) & Unadjusted odds ratio & $P$ value & Adjusted odds ratio & $P$ value \\
\hline Female sex & $121 / 1074(11.3)$ & $1.25(0.95-1.64)$ & 0.11 & $1.18(0.88-1.59)$ & 0.28 \\
\hline Age & & $1.011(0.999-1.024)$ & 0.08 & $1.01(0.996-1.023)$ & 0.18 \\
\hline Year of diagnosis & & $1.004(0.991-1.017)$ & 0.57 & $1.02(1.001-1.031)$ & 0.037 \\
\hline T-Stage & & & $<0.001$ & & $<0.001$ \\
\hline $1-2$ & $3 / 418(0.7)$ & 1 & & 1 & \\
\hline 3 & 134/1202 (11.1) & $17.4(5.50-55)$ & $<0.001$ & $15.6((4.90-49)$ & $<0.001$ \\
\hline 4 & $71 / 437(16.2)$ & $26.8(8.4-86)$ & $<0.001$ & $29.7(9.16-96)$ & $<0.001$ \\
\hline Unknown & $11 / 89(12.4)$ & $19.5(5.3-72)$ & $<0.001$ & $20.3(5.40-76)$ & $<0.001$ \\
\hline Location & & & $<0.001$ & & $<0.001$ \\
\hline Caecum & $31 / 288(10.8)$ & $7.80(2.35-26)$ & 0.001 & $6.40(1.90-22)$ & 0.003 \\
\hline Ascending colon & 26/310 (8.4) & $5.92(1.77-20)$ & 0.004 & $4.98(1.47-16.9)$ & 0.010 \\
\hline Right flexure & 8/99 (8.1) & $5.69(1.47-22)$ & 0.012 & $4.64(1.19-18.1)$ & 0.027 \\
\hline Transverse colon & 22/158 (13.9) & $10.5(3.07-36)$ & $<0.001$ & $9.39(2.72-32)$ & $<0.001$ \\
\hline Left flexure & 21/62 (33.9) & $33.1(9.44-116)$ & $<0.001$ & 27.5 (7.61-99) & $<0.001$ \\
\hline Descending colon & 19/93 (20.4) & $16.6(4.77-58)$ & $<0.001$ & $18.7(5.24-66)$ & $<0.001$ \\
\hline Sigmoid & 83/541 (15.3) & $11.7(3.66-38)$ & $<0.001$ & $11.8(3.63-38)$ & $<0.001$ \\
\hline Proximal rectum & $11 / 220(5.0)$ & $3.40(0.94-12.4)$ & 0.063 & $2.72(0.70-10.5)$ & 0.15 \\
\hline Middle rectum & $7 / 300(2.3)$ & $1.55(0.40-6.05)$ & 0.53 & $1.69(0.43-6.70)$ & 0.45 \\
\hline Distal rectum & 3/197 (1.5) & 1 & & 1 & \\
\hline
\end{tabular}

${ }^{a}$ Sex, age, year of diagnosis, and location of the primary tumour as covariates. Unadjusted, and adjusted for age, sex, year of diagnosis, and T-stage 
Table 5 Spontaneous colorectal perforation. Logistic regression with spontaneous colorectal perforation at presentation as dependent variable ${ }^{a}$

\begin{tabular}{|c|c|c|c|c|c|}
\hline & Perforations (\%) & Unadjusted odds ratio & $P$ value & Adjusted odds ratio & $P$ value \\
\hline Female sex & $30 / 1074(2.8)$ & $0.87(0.54-1.42)$ & 0.59 & $0.81(0.48-1.35)$ & 0.42 \\
\hline Age & & $0.99(0.97-1.005)$ & 0.13 & $0.98(0.96-1.01)$ & 0.14 \\
\hline Year of diagnosis & & $0.96(0.93-0.98)$ & $<0.001$ & $0.97(0.94-0.99)$ & 0.009 \\
\hline T-Stage & & & $<0.001$ & & $<0.001$ \\
\hline $1-2$ & $1 / 418(0.2)$ & 1 & & 1 & \\
\hline 3 & $27 / 1202(2.2)$ & $9.58(1.30-71)$ & 0.027 & $8.57(1.16-64)$ & 0.036 \\
\hline 4 & 38/437 (8.7) & $39.7(5.43-291)$ & $<0.001$ & $36.7(4.97-272)$ & $<0.001$ \\
\hline Unknown & 0/89 (0) & 0 & 0.997 & 0 & 0.997 \\
\hline \multicolumn{6}{|l|}{ Location } \\
\hline Caecum & 14/288 (4.9) & $10.0(1.31-77)$ & 0.027 & $9.25(1.18-73)$ & 0.034 \\
\hline Ascending colon & $5 / 310(1.6)$ & $3.12(0.37-28)$ & 0.03 & $3.59(0.41-31)$ & 0.25 \\
\hline Right flexure & 3/99 (3.0) & $6.13(0.63-60)$ & 0.12 & $5.17(0.52-52)$ & 0.16 \\
\hline Transverse colon & 2/158 (1.3) & $2.51(0.23-28)$ & 0.45 & $2.38(0.21-27)$ & 0.49 \\
\hline Left flexure & 2/62 (3.2) & $6.53(0.58-73)$ & 0.13 & $5,60(0.49-64)$ & 0.17 \\
\hline Descending colon & $5 / 93(5.4)$ & $11.14(1.28-97)$ & 0.029 & $13,7(1.54-123)$ & 0.019 \\
\hline Sigmoid & 26/541 (4.8) & $9.90(1.33-73)$ & 0.025 & 11.9 (1.57-90) & 0.017 \\
\hline Proximal rectum & $5 / 220(2.3)$ & $4.56(0.53-39)$ & 0.14 & $5.40(0.61-48)$ & 0.13 \\
\hline Middle rectum & $5 / 300(1.7)$ & 3.32 (0.39-29) & 0.28 & $2.68(0.29-25)$ & 0.38 \\
\hline Distal rectum & 1/197 (0.5) & 1 & & 1 & \\
\hline
\end{tabular}

a Sex, age, year of diagnosis, and location of the primary tumour as covariates. Unadjusted, and adjusted for age, sex, year of diagnosis, and T-stage. Distal rectal cancer was used as the reference location

obesity and diabetes in our county $[14,15]$, as well as in the rest of the country. Only $30 \%$ of the Norwegian population fulfil the recommended level of daily physical activity. On the other hand, there has been a decrease in daily smokers, from $36 \%$ in 1980 to $12 \%$ in 2018 [8].

Other reports have findings comparable to ours, attributing a large proportion of the increase in CRC incidence to preventable risk factors [16]. In the United Kingdom, one-third of all cancers are attributed to smoking, and one third to diet, nutrition, and physical activity [17]. Despite public initiatives to reduce the exposure to known risk factors - for example, advice regarding physical activity, smoking and diet - incidence levels have increased. From the present report, it seems that the effect of preventable risk factors on the incidence of CRC reached a peak around 2000-2010, with a more stable incidence in later years. Whether this is an effect of increased knowledge of risk factors and consequent behavioural changes in the population or indicates a maximum steady-state level of exposure to these risk factors in the population is disputable.

$\mathrm{CRC}$ is a disease with a multifactorial genesis primarily affecting the population in a sporadic manner, with a peak incidence in persons older than 70 years of age. The proportion of elderly patients has increased throughout our observation period, and this trend will continue in the future. Especially noticeable is the increasing number of patients above 85 years of age. According to the Norwegian national guidelines on CRC, a $33 \%$ increase in incidence is expected by $2024-2028$, mainly due to ageing of the population [5]. Our predictions coincide with the numbers presented in those guidelines.

Among the OECD countries, Norway is fourth in life expectancy. Other countries at the top of this list are also high HDI countries with high incidences of CRC (e.g., Switzerland, Japan, Australia, and Sweden) [18]. Norwegian life expectancy has increased by 7.5 years since the 1980s, and we found that $28 \%$ of the increased incidence in CRC could be attributed to increased age.

The Norwegian health care system is fully funded by the government. Hence, every Norwegian citizen has access to state-of-the-art medical services, and can seek medical help at any time, regardless of income. Colonoscopy and CT are nowadays, in contrast with the 1980s, considered low-threshold examinations. General practitioners can refer patients for these examinations within 9 calendar days (fast-track examination), if cancer is suspected. This may contribute to the high incidence levels, earlier stages detected, and decrease in the number of perforations at presentation observed in Norway recently. 
Decreasing incidences of CRC are observed in countries with established screening programs $[19,20]$. A national Norwegian screening program is currently being planned, enrolling patients at the age of 55 years. An increase in incidence rates must be expected before the incidence rates decline. Implementation of this screening program will not affect incidence among patients aged above 55 years at the time of implementation. During the first years after the Second World War, Norway experienced all-time-high birth rates. As life expectancy continues to increase in Norway, these large cohorts of elderly citizens not undergoing screening will result in an increased number of elderly CRC patients. In combination, these two factors will contribute to a peak in CRC incidence in the coming years. In a longer timeframe, however, we might observe falling incidence rates as the result of screening. Declining birth rates in Norway may augment this change in an even longer perspective.

\section{Stage}

In this study there was a trend towards earlier stages at diagnosis in recent decades. This might reflect more awareness of the disease among both patients and primary care physicians, better access to colonoscopy, and a more widespread use of CT with improved quality. These findings are contrary to other studies, which have reported unchanged or increasing rates of advanced stages with time [21-23]. Screening-detected cancer patients present with earlier stages of disease compared with non-screening-detected patients [24-28]. The patients in this study were all diagnosed before the introduction of systematic screening for CRC, indicating that the shift towards earlier stages at presentation will continue in the future. Distal localizations had earlier stages compared with proximal tumours, in accord with previous reports $[29,30]$.

\section{Colorectal obstruction and perforation}

Previous reports found emergency presentation of colorectal cancer in $9-32 \%$ of the patients, primarily due to colorectal obstruction and bowel perforation [31-37]. The incidence of complete obstruction has been reported as 8.3 to $22.9 \%$, and the perforation rates from 2.3 to $3.6 \%$ [31, 34, 36-42]. We found comparable rates, of 10.5 and $3.1 \%$ of the patients, respectively. Neither colorectal obstruction nor spontaneous perforation was associated with age in the present study, contrary to findings in previous reports [42]. Primary tumour localization to the left flexure had the highest rate of obstruction, at $34 \%$. Two other studies found that almost half of the tumours with this localization resulted in obstruction [42, 43]. The rate of spontaneous perforation diminished significantly during the study period. This might be due to a more effective health care system with shorter waiting times prior to surgery in patients presenting with obstructive symptoms or stenotic tumours at the time of colonoscopy.

\section{Strengths and weaknesses}

This study included a complete cohort of patients diagnosed with CRC over 37 years at a single institution serving a catchment area that remained unchanged throughout the study period. All patients with suspected CRC in our region were referred to our hospital for diagnostic work-up. Data were accessible at an individual level, and completed with data from the Norwegian Cancer Registry. Preoperative examinations, treatment and follow-up followed local guidelines (standardized policies) throughout the period, and similar guidelines were implemented at a national level in 2009. As all patients were included, we avoided selection bias. The population in our county is a stable population, suitable for epidemiologic studies [44]. The study reflects the epidemiology of elective as well as emergency admission of patients with colorectal cancer on a population basis.

The retrospective design implies certain weaknesses. The quality of the database was dependent on the quality of the individual records of the patients. By combining the data from the Norwegian cancer registry with our own database, we believe that the data used to calculate incidences were nearly complete. We may have missed some old, frail patients with symptoms of CRC who were treated at home or in nursing homes, without further investigation. The incidence in very old persons might thus be higher than reported.

Predictions of future cancer incidence depend upon a number of uncertain factors, and numbers must be interpreted with caution [45]. The numbers of CRC cases predicted to occur by 2030 and by 2040 in the present study assumed the same age- and genderspecific incidence rates as the means of the rates that were observed during 2007-2016.

\section{Future perspectives}

The most striking results of predicting future CRC cases occurring by 2030 and by 2040 were the continuous increase in CRC cases in our catchment area and the high numbers of octogenarians, the latter reflecting the impact of increased life expectancy in Norway in the coming years. Awareness of risk factors and systematic screening may reduce the incidence rates. Measures to also reduce the risk of CRC in the elderly non-screened parts of the population should be considered.

In the coming years, the Norwegian health care system must prepare for an increasing number of patients diagnosed with CRC. A large proportion of these patients will be $80-90$ years of age. The planned national 
screening program will not have an impact on CRC incidence among inhabitants aged above 55 years. In the screened part of the population, an initial increase in incidence and a shift towards earlier stages of CRC at presentation should be expected. In the long run, both screening and changes in the population may result in a decline in CRC incidence. Knowledge of these changes in patient volume and characteristics is imperative in order to establish a rational and effective organization of health services to accommodate these patients.

The current study demonstrates that a substantial number of cancer cases can be attributed to preventable causes. Increased knowledge concerning these causes is imperative to complete the puzzle regarding risk factors and disease development. The adverse development regarding obesity and lifestyle-related diseases accentuates the reality that current primary preventive strategies lack effectivity. Given the fact that more than two-thirds of CRC cases might be preventable, a key question is whether changes in these factors can be expected, and what impact this might have on disease development.

\section{Conclusion}

The CRC incidence rate increased by $90 \%$ from 1980 to 2016, mainly due to preventable factors. The incidence will continue to increase during the next two decades, primarily because of further ageing of the population. Continuous focus on preventive strategies, as well as awareness of changes in patient characteristics and volume are imperative to ensure adequate capacity, high quality and efficient patient care in the future.

\section{Abbreviations \\ Cl: Confidence interval; CRC: Colorectal cancer; HDI: Human development index; IR: Incidence rate; IRR: Incidence rate ratio; SD: Standard deviation}

\section{Acknowledgments}

We declare no conflicts of interest in connection with the current study.

\section{Authors' contributions}

$\varnothing \mathrm{H}$ : Made substantial contributions to the design of the work, interpretation of the data, and drafting and revising the manuscript. THE: Made substantial contributions to the design of the work, the analysis and interpretation of the data, and drafting and revising the manuscript. AX: Made substantial contributions to the design of the work, and revising the manuscript. SL: Made substantial contributions to the design of the work, analysis and interpretation of the data, and revising the manuscript. BHE: Made substantial contributions to the design of the work, the analysis and interpretation of the data, and drafting and revising the manuscript. All authors read and approved the final manuscript.

\section{Funding}

The research is funded by the Department of Surgery, Levanger Hospital, Nord-Trøndelag Hospital Trust, Norway. The funding bodies played no role in the design of the study and collection, analysis, and interpretation of data and in writing the manuscript.

\section{Availability of data and materials}

The dataset used for this study is located on a secure server in the Hospital's data system. Requests regarding the dataset can be addressed to Øystein Høydahl. The database was confirmed by comparing data from the
Norwegian Cancer Registry 1980-2016. Data obtained from the Norwegian Cancer Registry is available by application to the registry.

\section{Ethics approval and consent to participate}

The Regional Committee for Medical and Health Research Ethics (REC) gave permission for the study (2016/2172/REK midt).

\section{Consent for publication}

Not applicable.

\section{Competing interests}

The authors declare that they have no competing interests.

\section{Author details}

'Department of Surgery, Levanger Hospital, Nord-Trøndelag Hospital Trust, Levanger, Norway. ${ }^{2} \mathrm{IKOM}$ Department of Clinical and Molecular Medicine, NTNU, Norwegian University of Science and Technology, Trondheim, Norway. ${ }^{3}$ Regional Centre for Child and Youth Mental Health and Child Welfare - Central Norway, Faculty of Medicine, Department of Mental Health, Faculty of Medicine, Norwegian University of Science and Technology, Trondheim, Norway. ${ }^{4} \mathrm{Clinic}$ of Surgery, St Olavs Hospital, Trondheim University Hospital, Trondheim, Norway.

Received: 12 April 2020 Accepted: 28 October 2020

Published online: 10 November 2020

\section{References}

1. Bray F, Ferlay J, Soerjomataram I, Siegel RL, Torre LA, Jemal A. Global cancer statistics 2018: GLOBOCAN estimates of incidence and mortality worldwide for 36 cancers in 185 countries. CA Cancer J Clin. 2018;68:394-424. https:// doi.org/10.3322/caac.21492.

2. International Agency for Research on Cancer (IARC) (2018) Colorectal cancer. https://gco.iarc.fr/today/data/factsheets/cancers/10_8_9-Colorectumfact-sheet.pdf

3. Arnold M, Sierra MS, Laversanne M, Soerjomataram I, Jemal A, Bray F. Global patterns and trends in colorectal cancer incidence and mortality. Gut. 2017; 66:683-91. https://doi.org/10.1136/gutjin-2015-310912.

4. Danckert B FJ, Engholm G , Hansen HL, Johannesen TB, Khan S, Køtlum JE, Ólafsdóttir E, Schmidt LKH, Virtanen A, Storm HH. NORDCAN: Cancer Incidence, Mortality, Prevalence and Survival in the Nordic Countries, Version 82 (26032019) Association of the Nordic Cancer Registries Danish Cancer Society http://www.depiarcfr/nordcan/no/frameasp.

5. Helsedirektoratet Nasjonalt handlingsprogram med retningslinjer for diagnostikk, behandling og oppfølging av kreft i tykktarm og endetarm (2019) https://helsedirektoratet.no/retningslinjer/nasjonalthandlingsprogram-med-retningslinjer-for-diagnostikk-behandling-ogoppfolging-av-kreft-i-tykktarm-og-endetarm.

6. Kuipers EJ, Grady WM, Lieberman D, Seufferlein T, Sung JJ, Boelens PG, et al. Colorectal cancer. Nat Rev Dis Primers. 2015;1:15065. https://doi.org/10. 1038/nrdp.2015.65.

7. World Cancer Research Fund/American Institute for Cancer Research. Continuous update project expert report 2018. In: Diet, nutrition, physical activity and cancer: a global perspective; 2018. https://www.wcrf.org/ dietandcancer.

8. Statistics Norway (2019) http://www.ssb.no.

9. Holme O, Loberg M, Kalager M, Bretthauer M, Hernan MA, Aas E, et al. Effect of flexible sigmoidoscopy screening on colorectal cancer incidence and mortality: a randomized clinical trial. JAMA. 2014;312:606-15. https://doi.org/ 10.1001/jama.2014.8266.

10. Sobin LH, Wittekind C. TNM classification of malignant Tumours. 6th ed. New York: Wiley; 2002.

11. Glebov OK, Rodriguez LM, Nakahara K, Jenkins J, Cliatt J, Humbyrd CJ, et al. Distinguishing right from left colon by the pattern of gene expression. Cancer Epidemiol Biomark Prev. 2003;12:755-62.

12. Royston P, Altman DG. Regression using fractional polynomials of continuous covariates: parsimonious parametric modelling. J R Stat Soc: Ser C: Appl Stat. 1994;43:429-67.

13. Cancer Registry of Norway (2019) The statistics bank https://www. kreftregisteret.no/Registrene/data-og-statistikk/statistikkbank/.

14. Midthjell K, Kruger O, Holmen J, Tverdal A, Claudi T, Bjorndal A, et al. Rapid changes in the prevalence of obesity and known diabetes in an adult 
Norwegian population. The Nord-Trondelag health surveys: 1984-1986 and 1995-1997. Diabetes Care. 1999;22:1813-20. https://doi.org/10.2337/diacare. 22.11.1813.

15. Midthjell K, Lee CM, Langhammer A, Krokstad S, Holmen TL, Hveem K, et al. Trends in overweight and obesity over 22 years in a large adult population: the HUNT study, Norway. Clin Obes. 2013;3:12-20. https:/doi.org/10.1111/ cob.12009.

16. Platz EA, Willett WC, Colditz GA, Rimm EB, Spiegelman D, Giovannucci E. Proportion of colon cancer risk that might be preventable in a cohort of middle-aged US men. Cancer Causes Control. 2000;11:579-88.

17. Wiseman M. The second World Cancer Research Fund/American Institute for Cancer Research expert report. Food, nutrition, physical activity, and the prevention of cancer: a global perspective. Proc Nutr Soc. 2008;67:253-6. https://doi.org/10.1017/S002966510800712X.

18. OECD Data (2018) https://data.oecd.org/healthstat/life-expectancy-at-birth. htm.

19. Benson VS, Patnick J, Davies AK, Nadel MR, Smith RA, Atkin WS. International colorectal cancer screening network (2008) colorectal cancer screening: a comparison of 35 initiatives in 17 countries. Int J Cancer. 122:1357-67. https://doi.org/10.1002/ijc.23273.

20. Atkin WS, Edwards R, Kralj-Hans I, Wooldrage K, Hart AR, Northover JM, et al. Once-only flexible sigmoidoscopy screening in prevention of colorectal cancer: a multicentre randomised controlled trial. Lancet. 2010;375:1624-33. https://doi.org/10.1016/S0140-6736(10)60551-X.

21. Årsrapport 2017 med resultater og forbedringstiltak for Nasjonalt kvalitetsregister for tykk- og endetarmskreft. Oslo: Kreftregisteret, 2018.

22. Brouwer NPM, Bos A, Lemmens V, Tanis PJ, Hugen N, Nagtegaal ID, et al. An overview of 25 years of incidence, treatment and outcome of colorectal cancer patients. Int J Cancer. 2018;143:2758-66. https://doi.org/10.1002/ijc. 31785.

23. Scotland ISD. Cancer incidence and prevalence in Scotland (to December 2017) (2019): A National Statistics publication for Scotland; 2017.

24. de Neree Tot Babberich MPM, Vermeer NCA, Wouters M, van Grevenstein WMU, Peeters K, Dekker E, et al. Postoperative outcomes of screen-detected vs non-screen-detected colorectal cancer in the Netherlands. JAMA Surg. 2018;153:e183567. https://doi.org/10.1001/jamasurg.2018.3567.

25. Fitzpatrick-Lewis D, Ali MU, Warren R, Kenny M, Sherifali D, Raina P. Screening for colorectal cancer: a systematic review and meta-analysis. Clin Colorectal Cancer. 2016;15:298-313. https://doi.org/10.1016/j.clcc.2016.03. 003.

26. Friedrich K, Gruter L, Gotthardt D, Eisenbach C, Stremmel W, Scholl SG, et al. Survival in patients with colorectal cancer diagnosed by screening colonoscopy. Gastrointest Endosc. 2015;82:133-7. https://doi.org/10.1016/j. gie.2014.12.048.

27. Neely D, Campbell W, Davey P, Rodgers C, McCrory D. Colorectal cancer screening: the northern trust experience. Ulster Med J. 2013;82:160-3.

28. Schoen RE, Pinsky PF, Weissfeld JL, Yokochi LA, Church T, Laiyemo AO, et al. Colorectal-cancer incidence and mortality with screening flexible sigmoidoscopy. N Engl J Med. 2012;366:2345-57. https://doi.org/10.1056/ NEJMoa1114635

29. Yang J, Du XL, Li ST, Wang BY, Wu YY, Chen ZL, et al. Characteristics of differently located colorectal cancers support proximal and distal classification: a population-based study of 57,847 patients. PLoS One. 2016; 11:e0167540. https://doi.org/10.1371/journal.pone.0167540.

30. Cancer Registry of Norway. Cancer in Norway 2018 - Cancer incidence, mortality, survival and prevalence in Norway. Oslo: Cancer Registry of Norway; 2019.

31. Alvarez JA, Baldonedo RF, Bear IG, Truan N, Pire G, Alvarez P. Presentation, treatment, and multivariate analysis of risk factors for obstructive and perforative colorectal carcinoma. Am J Surg. 2005;190:376-82. https://doi. org/10.1016/j.amjsurg.2005.01.045.

32. Bowman KC, Tabrizian P, Telem DA, Boudourakis L, Divino CM. Health disparity in complicated colorectal cancer. Am Surg. 2010;76:164-7.

33. Gunnarsson H, Holm T, Ekholm A, Olsson LI. Emergency presentation of colon cancer is most frequent during summer. Color Dis. 2011;13:663-8. https://doi.org/10.1111/j.1463-1318.2010.02270.x.

34. Jestin P, Nilsson J, Heurgren M, Pahlman L, Glimelius B, Gunnarsson U. Emergency surgery for colonic cancer in a defined population. Br J Surg. 2005;92:94-100. https://doi.org/10.1002/bjs.4780.

35. Kundes F, Kement M, Cetin K, Kaptanoglu L, Kocaoglu A, Karahan M, et al. Evaluation of the patients with colorectal cancer undergoing emergent curative surgery. Springerplus. 2016;5:2024. https://doi.org/10.1186/s40064016-3725-9.

36. McArdle CS, Hole DJ. Emergency presentation of colorectal cancer is associated with poor 5-year survival. Br J Surg. 2004;91:605-9. https://doi. org/10.1002/bjs.4456.

37. Nascimbeni R, Ngassa H, Di Fabio F, Valloncini E, Di Betta E, Salerni B. Emergency surgery for complicated colorectal cancer. A two-decade trend analysis. Dig Surg. 2008;25:133-9. https://doi.org/10.1159/000128170.

38. Ahuja N, Chang D, Gearhart SL. Disparities in colon cancer presentation and in-hospital mortality in Maryland: a ten-year review. Ann Surg Oncol. 2007; 14:411-6. https://doi.org/10.1245/s10434-006-9130-9.

39. Biondo S, Marti-Rague J, Kreisler E, Pares D, Martin A, Navarro M, et al. A prospective study of outcomes of emergency and elective surgeries for complicated colonic cancer. Am J Surg. 2005;189:377-83. https://doi.org/10. 1016/j.amjsurg.2005.01.009

40. Liang PS, Chen TY, Giovannucci E. Cigarette smoking and colorectal cancer incidence and mortality: systematic review and meta-analysis. Int J Cancer. 2009;124:2406-15. https://doi.org/10.1002/ijc.24191.

41. Shibahara K, Orita H, Koga T, Kohno H, Sakata H, Kakeji Y, et al. Curative surgery improves the survival of patients with perforating colorectal cancer. Surg Today. 2010;40:1046-9. https://doi.org/10.1007/s00595-009-4155-x.

42. Boeding JRE, Ramphal W, Crolla R, Boonman-de Winter LJM, Gobardhan PD, Schreinemakers JMJ. lleus caused by obstructing colorectal cancer-impact on long-term survival. Int J Color Dis. 2018;33:1393-400. https://doi.org/10. 1007/s00384-018-3132-5.

43. Phillips RK, Hittinger R, Fry JS, Fielding LP. Malignant large bowel obstruction. Br J Surg. 1985;72:296-302. https://doi.org/10.1002/bjs. 1800720417.

44. Krokstad S, Langhammer A, Hveem K, Holmen TL, Midthjell K, Stene TR, et al. Cohort profile: the HUNT study, Norway. Int J Epidemiol. 2013;42:96877. https://doi.org/10.1093/ije/dys095.

45. Bray F, Moller B. Predicting the future burden of cancer. Nat Rev Cancer 2006;6:63-74. https://doi.org/10.1038/nrc1781.

\section{Publisher's Note}

Springer Nature remains neutral with regard to jurisdictional claims in published maps and institutional affiliations.
Ready to submit your research? Choose BMC and benefit from:
- fast, convenient online submission
- thorough peer review by experienced researchers in your field
- rapid publication on acceptance
- support for research data, including large and complex data types
- gold Open Access which fosters wider collaboration and increased citations
- maximum visibility for your research: over $100 \mathrm{M}$ website views per year
At BMC, research is always in progress.
Learn more biomedcentral.com/submissions 